\title{
Pendidikan Karakter Orang Tua terhadap Anak dalam Teks Jawa "Dongengipun Suwidak Loro"
}

\author{
R. Adi Deswijaya \\ Prodi Pendidikan Bahasa dan Sastra Daerah, Universitas Veteran Bangun Nusantara \\ E-mail: adides2016@gmail.com
}

Riwayat artikel: submit: 17 September 2021; revisi: 27 September 2021, diterima: 30 September 2021

\begin{abstract}
ABSTRAK
Tujuan dari penelitian ini untuk mendeskripsikan tentang bentuk-bentuk pendidikan karakter yang diberikan Mbok Randha Sambega kepada Suwidak Loro dalam teks Jawa Dongengipun Suwidak Loro. Penelitian ini merupakan penelitian kualitatif yang bersifat deskriptif. Data penelitian yang digunakan meliputi kata, frasa maupun kalimat yang berhubungan dengan pendidikan karakter, sedangkan teks Jawa Dongengipun Suwidak Loro sebagai sumber datanya. Teknik pengumpulan data menggunakan cara pustaka, simak dan catat. Menyimak semua data yang berhubungan dengan pendidikan karakter, kemudian memilah dan mencatat data tersebut sehingga dapat dianalisis untuk mendapatkan hasil pembahasan dari penelitian ini. Teknik analisis menggunakan analisis deskriptif untuk mendapatkan hasil pembahasan dalam penelitian ini. Penelitian ini menghasilkan pembahasan bentuk-bentuk pendidikan yang dilakukan Mbok Randha Sambega, antara lain: (1) kasih sayang; (2) mendoakan anak untuk yang terbaik; (3) tidak pernah mencela anak; dan (4) selalu berpikir positif.
\end{abstract}

Kata kunci: karya sastra, pendidikan karakter orang tua, dongeng suwidak loro

\section{ABSTRACT}

The purpose of this study is to describe the forms of character education given by Mbok Randha Sambega to Suwidak Loro in the Javanese text Dongengipun Suwidak Loro. This research is a descriptive qualitative research. The research data used include words, phrases and sentences related to character education, while the Javanese text of the Dongengipun Suwidak Loro as the data source. The data collection technique uses the library, listen and note method. Listening to all data related to character education, then sorting and recording the data so that it can be analyzed to get the results of the discussion of this research. The analysis technique uses descriptive analysis to get the results of the discussion in this study. This study resulted in a discussion of the forms of education carried out by Mbok Randha Sambega, including: (1) compassion; (2) wishing children for the best; (3) never criticizing children; and (4) always thinking positively.

Keywords: literary works, parental character education, suwidak loro fairy tales 
Deswijaya. A.R (2021). Pendidikan Karakter Orang Tua Terhadap Anak dalam Teks Jawa Dongengipun Suwidak Loro. Edudikara: Jurnal Pendidikan dan Pembelajaran, 6(3), 235-243.

\section{PENDAHULUAN}

Teknologi semakin merebak, kejahatan pun semakin meledak. Gejala kemerosotan moral semakin tampak memprihatinkan. Pertikaian, pencurian, perampokan, pornografi, anak hamil di bawah umur atau di luar nikah, pembunuhan serta sebagainya semakin menjamur di kehidupan milenial ini. Anak bertikai dengan orang tua, orang tua bertikai dengan anak, dan bahkan saling membunuh demi tercapainya keinginan pribadi.

Hilangnya rasa kemanusiaan menjadi tranding record yang harus segera ditangani oleh pemerintah. Meskipun pemerintah telah mengeluarkan Undang-Undang Nomor 20 Tahun 2003 Pasal 3 (RI, 2003) tentang Pendidikan Nasional yang berfungsi sebagai pembentuk karakter dan peradaban bangsa yang dapat mencerdaskan kehidupan bangsa, namun fenomena-fenomena pengikisan moral pada anak muda masih sangat mengkhawatirkan di sekitar kehidupan kita.

Canggihnya teknologi yang semakin memberikan fitur-fitur siap saji telah merubah karakter anak-anak pada jaman sekarang. Karakter pemalas dan mudah marah telah hadir pada diri mereka. Mereka asyik bermain tanpa menghiraukan orang-orang di sekitarnya. Kehadiran teknologi melalui handphone android mereka salah gunakan hanya sebagai hiburan, bukan sebagai piranti untuk browsing kawruh.

Fakta-fakta seperti inilah yang dapat membahayakan karakter dan peradaban bangsa. Salah satu contoh pemberitaan yang mengagetkan akhir-akhir ini adalah pembunuhan terhadap anak kandung yang dilakukan oleh kedua orang tuanya sendiri. Seusia anak yang seharusnya mendapatkan perlindungan, perhatian kasih sayang dan didikan dari kedua orang tuanya, telah hilang oleh kekejaman kedua orang tua kandung hanya demi meladeni pesugihannya.

Masyarakat jaman sekarang sedang menghadapi dekadensi moral atau karakter yang jaun sangat kompleks jika dibandingkan dengan keadaan jaman dahulu (Cornelia, 2019) . Kejadian tersebut menandakan bahwasanya pendidikan karakter semestinya tidak hanya untuk generasi muda, namun generasi tua pun harus menjadi sasaran dalam pendidikan karakter. Minimnya ekonomi merupakan salah satu pemicu psikologi seseorang dalam sebuah keluarga untuk berbuat ke arah tindakan-tindakan negatif.

Derasnya globalisasi dan menggejalanya gaya hidup yang bertentangan dengan nilai-nilai moral, agama dan budaya lokal juga berdampak pada perubahan karakter seseorang. Max dalam Scheller dalam Sutarjo membagi nilai menjadi empat tingkatan yaitu: nilai kenikmatan, nilai kehidupan, nilai kejiwaan, dan nilai kerohanian (Sutarjo Adisusilo, 2013). Perkembangan teknologi sesungguhnya besar manfaatnya bagi kehidupan kita, selama kita dapat menggunakannya untuk keperluan pemanfaatan ilmu secara benar dan tepat sasaran.

Pentingnya pendidikan karakter bagi seorang anak harus dimulai dari lingkungan keluarga terlebih dahulu. Banyak cara yang dapat dilakukan orang tua untuk menyampaikan pendidikan karakter tersebut bagi anak. Keberhasilan pendidikan karakter terhadap anak sangat tergantung pada bagaimana cara orang tua mendidik. Orang tua seharusnya dapat menjadi ing ngarsa sung tuladha, ing madya mangun karsa, tut wuri handayani. Orang tua seharusnya dapat memberikan contoh, memberikan arahan dan dorongan bagi anak agar ke depan memiliki karakter terpuji yang dapat dibanggakan kedua orang tuanya.

Surat At Tahrim ayat 6 yang berbunyi "wahai orang-orang yang beriman, peliharalah dirimu dan keluargamu dari Api Neraka", tersirat jelas adanya perintah untuk selalu menciptakan dan atau memelihara karakter-karakter terpuji di dalam lingkungan keluarga kita jika ingin terselamatkan dari api neraka. Ayat tersebut secara langsung merupakan perintah untuk selalu menjaga sifat atau karakter-karakter terpuji di dalam sebuah keluarga.

Karakter (Pratiwi, 2018) merupakan keadaan sebenarnya yang dimiliki individu yang dapat membedakan pribadinya dengan individu lainnya. Karakter anak akan berubah menyesuaikan karakter orang tua disaat mendidik atau nggulawenthah. Keluarga atau orang tua merupakan 
Deswijaya. A.R (2021). Pendidikan Karakter Orang Tua Terhadap Anak dalam Teks Jawa Dongengipun Suwidak Loro. Edudikara: Jurnal Pendidikan dan Pembelajaran, 6(3), 235-243.

pendidik utama informal, sedangkan guru adalah pendidik kedua secara formal di sekolahan. Pendidikan karakter yang diberikan guru kepada anak didik di sekolah, tidak cukup hanya dengan membiasakan diri dengan tatakrama dan subasita ketika bertatap muka baik di dalam kelas maupun di luar kelas.

Karya sastra merupakan cara lain yang dapat digunakan sebagai bahan pembelajaran nilai-nilai karakter. Pembelajaran bahan ajar bermediakan karya sastra pada prinsipnya dapat diterapkan, karena karya sastra sendiri tak lepas dari kandungannya berupa nilai-nilai karakter yang dapat diimplementasikan ke dalam kehidupan ini (Everardus Ngarbingan, Abdul Hafid, 2021). Media karya sastra merupakan salah satu cara yang dapat digunakan sebagai bahan pembelajaran pendidikan karakter, sebagai contoh yaitu karya sastra Jawa berbentuk dongeng anak.

Karya sastra Jawa berbentuk dongeng ini sangat efektif bagi anak didik. Anak didik tidak hanya mendengarkan atau menyimak dongeng yang disampaikan gurunya, namun anak didik diharapkan dapat memberikan beberapa pendapatnya tentang karakter-karakter apa saja yang telah dilakukan oleh tokoh-tokoh di dalam dongeng tersebut.

Pendidikan karakter berobjekkan sastra anak atau dongeng bocah ini sebenarnya tidak hanya dilakukan di tingkat formal sekolahan saja. Jaman dahulu, ketika anak-anak hendak beranjak tidur, orang tua selalu beralih profesi sebagai pendongeng ulung sebagai pengantar tidur. Cerita-cerita yang disampaikan orang tua jaman dahulu selalu dengan menyelipkan ajaran-ajaran budi pekerti atau karakter, sehingga anak akan selalu mengingat tokoh-tokoh di dalam cerita tersebut serta apa yang dilakukannya. Sewaktu membaca atau mendengar sebuah cerita, anak otomatis akan berpetualang secara imajinatif, diajak melakukan eksplorasi ke dunia yang belum dikenalnya dengan menawarkan berbagai pengalaman hidup (Nurgiyantoro, 2016).

Pendidikan karakter bagi anak telah banyak dilakukan oleh peneliti-peneliti sebelumnya. Peneliti Sultan Hadi Prabowo dan kawan-kawan menilik pendidikan karakter anak melalui perspektif pendidikan Islam (Sultan Hadi Prabowo, Agus Fakhruddin, 2020). Sultan menyampaikan bahwa orang tua berperan membentuk karakter anak ke arah insan paripurna, yaitu sebagai pendidik, fasilitator, pendamping, pengawas, motivator dan figur yang dapat dicontoh anak.

Peneliti lain menyimpulkan bahwa penanaman pendidikan karakter sebaiknya: (1) ditanamkan oleh keluarga, sekolahan dan masyarakat kepada anak sejak dini, (2) pendidikan karakter merupakan pengembangan nilai-nilai pandangan hidup atau idiologi bangsa Indonesia, budaya, agama, dan yang terumuskan dalam tujuan pendidikan nasional, serta (3) konsep diri anak terbentuk atas persepsi seseorang terkait sikap orang lain terhadap dirinya (Diananda, 2018).

Berlatarbelakang fenomena-fenomena di depan dan juga berlandaskan penelitian terdahulu, maka penelitian ini mengambil judul Pendidikan Karakter Orang Tua Terhadap Anak di dalam Teks Jawa Dongengipun Suwidak Loro. Penelitian ini sangat penting untuk diteliti karena isi teks Dongengipun Suwidak Loro yang menjadi objek kajian atau sumber data penelitian ini sangat syarat akan adanya pendidikan karakter yang disampaikan tokoh dongeng Mbok Randha Sambega dalam mendidik anak wanitanya yang bernama Suwidak Loro.

Didikan karakter Mbok Randha Sambega terhadap putrinya sangat bertentangan sekali dengan fakta yang terjadi di kehidupan jaman sekarang. Begitu asih dan sayangnya Mbok Randha Sambega terhadap putri satu-satunya walaupun sekujur tubuh putrinya cacat dan tidak dapat dikatakan mirip manusia.

Permasalahan yang terdapat di dalam penelitian ini adalah pendidikan seperti apakah yang diberikan Mbok Randha Sambega dalam mendidik putrinya? Tujuan penelitian ini tidak lain untuk menguraikan beberapa tipe pendidikan karakter yang digunakan tokoh Mbok Randha Sambega dalam usahanya mendidik putrinya yang bernama Suwidak Loro. 
Deswijaya. A.R (2021). Pendidikan Karakter Orang Tua Terhadap Anak dalam Teks Jawa Dongengipun Suwidak Loro. Edudikara: Jurnal Pendidikan dan Pembelajaran, 6(3), 235-243.

\section{METODE}

Jenis penelitian ini menggunakan penelitian kualitatif deskriptif. Penelitian kualitatif bertujuan menggali secara mendalam sebuah gejala, fakta maupun realita yang dialami manusia, dan pelaksanaannya dilakukan secara bertahap(Raco, 2010). Bersifat deskriptif karena berusaha menguraikan dan menganalisis data yang berupa kata, frasa maupun kalimat yang terdapat di dalam teks Jawa Dongengipun Suwidak Loro kaitannya dengan pendidikan karakter. Penelitian yang bersifat deskriptif mengandalkan data berupa teks (Raco, 2010).

Sumber data primer penelitian ini adalah teks Jawa cetak koleksi Yayasan Sastra Lestari Surakarta yang berjudul Kumpulan Dongeng. Judul Kumpulan Dongeng ini adalah pemberian nama dari Yayasan Sastra Lestari Surakarta sendiri. Hal ini disebabkan sampul luar teks sudah hilang. Teks Jawa cetak Kumpulan Dongeng memuat 2 judul teks, yaitu Dongengipun Suwidak Loro karya dari Dawud dan Layang Dongenge Wong Kuna karya Mas Harja Saputra. Penelitian ini mengambil sampel judul Dongengipun Suwidak Loro sebagai objek penelitiannya.

Teknik pengumpulan data dilakukan dengan cara teknik pustaka dilanjutkan simak dan catat. Teknik pustaka mengambil dari sumber tertulis untuk memperoleh data yang mendukung kegiatan analisis. Simak berkaitan pembacaan secara teliti pada teks, sedangkan catat adalah langkah mengumpulkan semua data yang ada hubungannya dengan pendidikan karakter. Teknik analisis penelitian ini menggunakan analisis deskriptif.

\section{HASIL DAN PEMBAHASAN}

Langkah menyimak dan mencatat telah digunakan untuk pengumpulan data, sedangkan langkah selanjutnya adalah analisis deskriptif dari isi teks Dongengipun Suwidak Loro. Melalui analisis konten yang berjenis deskriptif, ditemukan beberapa pendidikan karakter yang terdapat pada pribadi Mbok Randha Sawega, di antaranya:

\section{Kasih Sayang}

Kasih sayang merupakan insting alamiah seorang ibu terhadap putra-putrinya. Apa pun yang terjadi pada diri putra-putrinya, ibu akan selalu melindungi dan mengasuhnya hingga dewasa. Kasih sayang seorang Ibu tidak akan putus untuk anaknya, meskipun anaknya dalam keadaan tidak sempurna tubuhnya (cacat) atau pun tidak menghormatinya.

Kasih sayang seorang ibu ini terlihat pada tokoh Mbok Randha Sambega terhadap putri satu-satunya yang bernama Suwidak Loro.

(1) Bok Răndha Sambega gadhah anak èstri satunggil nama pun Suwidak Loro. Mila nama makatên, awit rambutipun namung wontên suwidak êlêr, untunipun namung kalih iji, tur warninipun botên mèmpêr tiyang kathah, bêbasan kados gêndruwo thethekan. Sirahipun pating brênjul, bathukipun anonong, mripat malêthus, irung tèsèk, rai mungkal gêrang, lambe nyoro, gulu lêkêk, pundhak barojol, tangan ceko, bokong tepos, suku penthong, lampahipun impur.

Ingkang katêdha ing sadintênipun ugi sanès kalihan tiyang kathah, kados ta: cabuk, gêrèh pèthèk, gorengan botor, tuwin cêngkaruk gimbal. Dados mèh kados pirantosipun tiyang mêthil anylamêti pantun wontên ing sabin ingkang badhe wiwit kapugut. Dene bok răndha awis nêdha, sarta awis-awis tilêm. Tiyang kalih wau botên nate mêdal saking ing griya, namung anênuwun dhatêng Ingkang Maha Kuwasa, supados kaparênga ingkang dados panuwunipun.

Ing wanci dalu sabên sawung kaluruk, bok răndha anggugah anakipun dipun kudang. Pangudangipun makatên: $O$, Allah, anakku ayu dhewe, ênggèr, Suwidak Loro tangia kowe dak kudang. Anakku besuk bakal dipundhut dadi garwaning ratu. Punika rambah-rambah ngantos dumuginipun ing wanci byar. (HIm.3-4).

Terjemahan: 
Deswijaya. A.R (2021). Pendidikan Karakter Orang Tua Terhadap Anak dalam Teks Jawa Dongengipun Suwidak Loro. Edudikara: Jurnal Pendidikan dan Pembelajaran, 6(3), 235-243.

\begin{abstract}
'Mbok Randa Sambega memiliki satu orang anak perempuan bernama Suwidak Loro. Bernama demikian karena jumlah rambutnya ada enam puluh helai, giginya hanya dua buah, dan wajahnya tidak layak seperti kebanyakan orang, perumpamaan mirip gandarwa. Kepalanya tidak rata, jidatnya nonong, mata menonjol, hidung pesek, wajah mirip ungkal berlubang, bibir mirip kecoa, leher pendek, bahu besar, tangan bengkok, pantat tipis, kaki bengkok, jika berjalan kakinya agak melebar.

Sehari-hari yang dimakan juga bukan seperti kebanyakan orang, antara lain: cabuk, gereh petek, gorengan botor, dan cengkaruk gimbal. Sehingga mirip dengan peralatan orang selamatan memetik padi di sawah yang hendak mulai diambil. Adapun Mbok Randha jarang-jarang makan, serta jarang-jarang tidur. Kedua orang tersebut tidak pernah keluar dari rumah, hanya memohon doa kepada Sang Kuasa agar dikabulkan apa yang menjadi permintaannya. Ketika malam hari saat ayam jantan berkokok, bok randa membangunkan anaknya kemudian ditimang-timang disertai harapan. Menimang-nimang sambil berkata dan berharap sebagai berikut: Ya Allah, anakku yang paling cantik, nak, Suwidak Loro, bangunlah, kamu yang selalu aku doakan. Anakku, besok kamu pasti akan diperistri oleh seorang raja. Hal ini dilakukan berulang-ulang sampai fajar menyingsing.'
\end{abstract}

Data (1) menunjukkan adanya nilai pendidikan yang berbentuk kasih sayang seorang lbu kepada putrinya meskipun dalam keadaan yang tidak memungkinkan. Mbok Randha Sambega tetap menyayangi dan mengasihi putrinya, meskipun keadaan tubuh putrinya penuh dengan cacat sehingga tidak layak jika dikatakan seperti manusia.

Kasih sayang ini tampak ketika Mbok Randha selalu menimang-nimang Suwidak Loro setiap hari, sejak petang sampai pagi hari tanpa lelah, disertai doa yang terbaik kelak untuk putrinya. Selain itu kasih sayang Mbok Randha ditunjukkan pula saat menimang putrinya dengan kata-kata anakku ayu dhewe, ênggèr 'anakku yang paling cantik, Nak.'

Pemberian bekal makanan dari Mbok Randha untuk putrinya merupakan bentuk kasih sayang orang tua terhadap anaknya. Mbok Randha begitu perhatian kepada putrinya. Hal ini terdapat pada data (2) di bawah ini.

(2) Joli kalêbêtakên, bok răndha wicantên dhatêng anakipun: Wis ênggèr malêbua ing jêro joli kene, dak kuncine, aja pati-pati kobukak, yèn durung têkan ing kraton. Iki pangananmu aja nganti kari. (HI.10)

Terjemahan:

Joli kemudian dimasukkan, mbok randha berbicara pada putrinya: Sudah ngger, masuklah ke dalam joli ini, akan aku kunci, jangan sampai engkau buka, jika belum sampai di keraton. Ini bekal makananmu jangan sampai tertinggal.'

\title{
2. Mendoakan Anak untuk yang Terbaik
}

(3) Tiyang kalih wau botên nate mêdal saking ing griya, namung anênuwun dhatêng Ingkang Maha Kuwasa, supados kaparênga ingkang dados panuwunipun. (HIm.4)

Terjemahan:

Kedua orang tersebut tidak pernah keluar dari rumah, hanya memohon doa kepada Sang Kuasa agar dikabulkan apa yang menjadi permintaannya.

Data (3) di atas menunjukkan bahwa Mbok Randha Sambega tidak bosan-bosannya selalu berdoa kepada Yang Maha Kuasa agar apa yang diharapkan dalam doanya dapat terkabul. Doa adalah senjata bagi Mbok Randha Sambega.

Bentuk doa terbaik Mbok Randha Sambega bagi putrinya terdapat juga dalam katakatanya disaat menimang putrinya. Doa terbaik Mbok Randha Sambega agar nantinya putrinya 
Deswijaya. A.R (2021). Pendidikan Karakter Orang Tua Terhadap Anak dalam Teks Jawa Dongengipun Suwidak Loro. Edudikara: Jurnal Pendidikan dan Pembelajaran, 6(3), 235-243.

dapat diperistri oleh seorang raja. Doa harapan ini sangat bertentangan dengan keadaan sebenarnya. Tidak masuk akal jika seorang putri yang memiliki kekurang sempurnaan pada seluruh tubuhnya dapat diperistri oleh seorang raja. Namun, Mbok Randha Sambega tetap berkeyakinan bahwa doa harapan yang diberikan untuk putrinya dapat terkabul. Fenomena ini tergambarkan pada data (4) berikut.

(4) Ing wanci dalu sabên sawung kaluruk, bok răndha anggugah anakipun dipun kudang. Pangudangipun makatên: $O$, Allah, anakku ayu dhewe, ênggèr, Suwidak Loro tangia kowe dak kudang. Anakku besuk bakal dipundhut dadi garwaning ratu. Punika rambah-rambah ngantos dumuginipun ing wanci byar. (HI.4)

Terjemahan:

Ketika malam hari saat ayam jantan berkokok, bok randha membangunkan anaknya kemudian ditimang-timang disertai harapan. Menimang-nimang sambil berkata dan berharap sebagai berikut: Ya Allah, anakku yang paling cantik, nak, Suwidak Loro, bangunlah, kamu yang selalu aku doakan. Anakku, besok kamu pasti akan diperistri oleh seorang raja. Hal ini dilakukan berulangulang sampai fajar menyingsing.'

Jika dilihat sepintas data (4) di atas, dapat digambarkan adanya sebuah kegiatan tengah malam yang dilakukan oleh Mbok Randha Sambega, yaitu bangun dari tidurnya serta membangunkan anaknya dengan menimang-nimang disertai doa harapan. Kegiatan bangun tengah malam ini dapat dipersepsikan sebagai kegiatan ibadah sholat malam yang dilakukan Mbok Randha Sambega hingga fajar menyingsing. Doa harapan yang dipanjatkannya tidak lain hanyalah untuk putri satu-satunya, yaitu Suwidak Loro. Kegiatan ini dilakukannya di saat menimang anaknya disertai doa harapan secara berulang-ulang atau istiqomah sampai fajar menyingsing.

Doa terbaik seorang ibu untuk anaknya juga terdapat pada data (5) di bawah ini. Data (5) memperlihatkan ketika Suwidak Loro memohon doa restu kepada ibunya. Mbok Randha Sawega pun memberikan doa restu kepada Suwidak Loro agar putrinya kelak diperistri oleh sang raja. Dorongan doa dari Mbok Randha untuk putrinya ini, dia lakukan dengan mengurangi makan dan tidur.

(5) Wangsulanipun Suwidak Loro: lya biyung, aku anjaluk pangèstu. Wangsulanipun biyungipun: lya ênggèr, muga-muga dikarsakake marang sang nata, dak rewangi ora turu ora mangan. (HI.10)

\section{Terjemahan:}

Suwidak Loro menjawab: Baik Bu, saya mohon doa restu. Ibunya menjawab: Iya Nak, semoga kamu diterima oleh sang raja, sudah aku bantu tidak tidur dan tidak makan.

\section{Tidak Pernah Mencela Anak}

Mbok Randha Sambega sebagai seorang ibu yang memiliki putri tidak sempurna, tidak pernah sama sekali mengucapkan kata-kata celaan terhadap putrinya. Apa yang diucapkannya untuk putrinya selalu berbentuk pujian, walau pun fakta yang ada tidak sedemikian.

Hal ini terjadi pada data (6) di bawah yang menunjukkan pujian Mbok Randha kepada putrinya dengan perkataan anakku ayu dhewe 'anakku paling cantik'. Tampak Mbok Randha ketika berada di depan putrinya selalu menutup-nutupi kekurangan yang terdapat pada putrinya, dan tidak pernah menampakkan kekecewaan.

(6) Pangudangipun makatên: $O$, Allah, anakku ayu dhewe, ênggèr, Suwidak Loro tangia kowe dak kudang. Anakku besuk bakal dipundhut dadi garwaning ratu. Punika rambah-rambah ngantos dumuginipun ing wanci byar. (HIm.4) 
Deswijaya. A.R (2021). Pendidikan Karakter Orang Tua Terhadap Anak dalam Teks Jawa Dongengipun Suwidak Loro. Edudikara: Jurnal Pendidikan dan Pembelajaran, 6(3), 235-243.

Terjemahan:

Menimang-nimang sambil berkata dan berharap sebagai berikut: Ya Allah, anakku yang paling cantik, nak, Suwidak Loro, bangunlah, kamu yang selalu aku doakan. Anakku, besok kamu pasti akan diperistri oleh seorang raja. Hal ini dilakukan berulang-ulang sampai fajar menyingsing.'

Seperti halnya data (6) di atas, data (7) di bawah ini pun menampakkan adanya rasa bahagia Mbok Randha Sawega sewaktu mendengar putrinya hendak diperistri raja. Mbok Randha berusaha menutup-nutupi kekurangan putrinya kepada utusan raja dengan perkataan Anak kawula ayunipun botên kantên-kantênan 'Anak hamba cantiknya luar biasa, tidak mungkin aku tunjuk-tunjukkan.'

(7) Lampahipun wontên ing margi botên kacariyosakên, enggalipun sampun dumugi ing padhêkahan Sidhangmiring, kyai patih utusan animbali Bok Răndha Sambega kapurih mêdal. Ingkang kautus sandika mangkat, dumugi ing griyanipun bok răndha, andhawuhakên timbalan, cêkakipun bok răndha sampun kerid dumugi ing ngarsanipun kyai patih, nuntên kadhawuhan makatên: Hèh, Bok Răndha Sambega, aku kautus dening sang nata, anglamar anakmu, sumêdya kapundhut garwa, mara anakmu wêtokna dak dandanane. Yèn wis dak lêbokake ing joli, banjur dak unjukake marang ngarsane sang prabu. Aturipun Bok Răndha Sambega: Anak kawula ayunipun botên kantên-kantênan, kathik katêdah-têdahakên. (HI.8-9)

Terjemahan:

'Perjalanannya di tengah jalan tidak diceritakan, akhirnya sampai di desa Sidangmiring. Kyai Patih memerintahkan untuk memanggil Mbok Randha Sawega agar keluar. Yang diperintah segera berangkat melaksanakan tugas. Sesampainya di rumah mbok randha, dipanggilnya mbok randha. Singkat cerita Mbok Randha Sambega dikawal menuju di depan kyai patih, kemudian diperintah: Hai, Mbok Randha Sambega, aku diutus oleh sang raja untuk melamar anakmu, hendak diperistri. Segera bawa ke sini anakmu untuk kurias. Jika sudah akan aku masukkan joli, kemudian aku haturkan kepada sang prabu. Mbok Randha menjawab: Anak hamba cantiknya luar biasa, tidak mungkin aku tunjuk-tunjukkan.'

\section{Selalu Berpikir Positif (Tidak Memperdulikan Cemoohan Orang Lain)}

Ejekan, makian dan sumpah serapah yang keluar dari para tetangganya, oleh Mbok Rondha Sambega tidak digubrisnya. Dia tetap menimang-nimang anaknya dengan doa-doa harapan. Keadaan ini menunjukkan karakter Mbok Randha Sawega yang tetap bertahan dalam kesabarannya dan mampu menahan amarah, meskipun banyak cacian menghadapinya. Gambaran keadaan seperti ini muncul pada data (8) di bawah ini.

(8) Kocapa, tangganipun ingkang mirêng ing pangudanging anakipun sami gêthing sadaya sarta muring-muring sangêt, awit tanpa măngsa anggènipun angudang, wontên ingkang mungêl asora kalihan nosot-nosotakên makatên: Sambêr blêdhèg, Bok Răndha Sambega kowe. Wong angudang anake bae kok tanpa wayah, iki rak lagi wayahe wong turu anglêr, nganggo kowe angudang anakmu, tur anakmu iku ayua, wong rupane kaya gêndruwo thethekan, kathik olèhe angudang digarwa ing ratu, masa kalakona ora. Ing ngriku bok răndha anggènipun angudang botên kèndêl, malah saya sêru. Botên karèwès ing ujaring tangganipun. Wasana wontên satunggiling tangganipun ingkang muring-muring sarta nêpsu sangêt, botên narimah sumêdya anggigat dhumatêng ngarsaning sang nata (HI.4-5).

\section{Terjemahan:}

Diceritakan tetangganya yang mendengar timangan doa harapan Mbok Randha Sawega, merasa tidak senang semua dan marah-marah, karena menimangnya tidak mengenal waktu. Ada yang berteriak seraya menyumpah serapahi: Samber bledheg (tersambar petir), kamu mbok Randha Sawega! Menimang-nimang anak tanpa melihat waktu, ini kan masih saatnya orang sedang tidur 
Deswijaya. A.R (2021). Pendidikan Karakter Orang Tua Terhadap Anak dalam Teks Jawa Dongengipun Suwidak Loro. Edudikara: Jurnal Pendidikan dan Pembelajaran, 6(3), 235-243.

nyenyak, pakai nimang-nimang anakmu segala, lagi pula apakah anakmu cantik, wajah saja mirip genderuwo, kok bisa-bisanya didoakan kelak diperistri raja, tidak masuk akal. Mbok Randha mendengar teriakan tetangga tetap melanjutkan timang-timangnya, bahkan semakin keras. Tidak menggubris apa yang diucapkan tetangganya. Akhirnya ada salah satu tetangganya yang memakimaki dengan sangat emosional, tidak terima hendak mengajukan gugatan kepada sang raja.

\section{SIMPULAN DAN SARAN}

Penelitian ini bertujuan untuk mengetahui pendidikan karakter yang digunakan Mbok Randha Sambega dalam mendidik putrinya. Pendidikan karakter Mbok Randha Sawega terhadap putrinya yang bernama Suwidak Loro dalam teks Jawa Dongengipun Suwidak Loro lebih didominasi nilai-nilai religius yang berhubungan dengan Allah sebagai tempat mengadu.

Teks Dongengipun Suwidak Loro ini sangat cocok jika diimplementasikan ke dalam media pembelajaran di sekolahan-sekolahan, karena mengandung ajaran karakter yang sangat luhur yang telah dicontohkan tokoh Mbok Randha Sawega sebagai orang tua yang sangat bijak. Ajaran ini juga dapat menjadi kaca benggala bagi semua orang tua tentang bagaimana cara mendidik dan memperlakukan anak secara bijak.

Pendidikan karakter Mbok Randha Sawega di dalam teks Jawa Dongengipun Suwidak Loro meliputi: kasih sayang, mendoakan anak untuk yang terbaik, tidak pernah mencela anak, dan selalu berpikir positif (tidak memperdulikan cemoohan rang lain). Pendidikan karakter yang dilakukan Mbok Randha Sawega selaku orang tua ini perlu dicontoh dan dapat diimplementasikan ke dalam kehidupan jaman sekarang, demikian pula bagi pembelajaran di sekolahan.

Pendidikan karakter dalam Dongengipun Suwidak Loro sangat tepat jika tidak hanya ditujukan untuk anak, tetapi ditujukan pula untuk semua orang tua yang turut andil dalam mendidik anak. Karakter Mbok Randha Sawega patut untuk dijadikan contoh bagi semua orang tua.

Penelitian ini masih terdapat kekurangannya jika dilihat dari penelitian terdahulu maupun dari isi teks Jawa tersebut. Penelitian ini hanya menfokuskan pada pendidikan karakter Mbok Randha Sawega, sedangkan pendidikan karakter dari tokoh lainnya belum menjadi sasaran penelitian ini.

\section{REFERENSI}

Cornelia, T. S. (2019). Hubungan Antara Tingkat Pendidikan Orang Tua dan Keakraban Orangtua dengan Anak di RumahTerhadap Karakter Peserta Didik di Kelas IV SDN 066048 Medan Helvetia T.A 20182019. Komunikologi: Jurnal Pengembangan Ilmu Komunikasi Dan Sosial, 3(1), 59-68.

Diananda, A. (2018). Urgensi Pendidikan Karakter Dalam Pembentukan Konsep Diri Anak. 1(2), $1-21$.

Everardus Ngarbingan, Abdul Hafid, I. M. (2021). Analisis Karakter Tokoh dan Kandungan Nilai Karakter Dalam Novel Anak Sejuta Bintangkarya Akmal Nasery Basral. Jurnal Frasa: Jurnal Keilmuan Bahasa, Sastra, Dan Pengajarannya, 2(1), 75-88. Retrieved from https://unimuda.e-journal.id/jurnalbahasaindonesia/article/view/960

Nurgiyantoro, B. (2016). Sastra Anak (Keempat). Retrieved from https://drive.google.com/file/d/1S1LitqkIDUrD0zzQ19ig96x0UQIWCzp0/view?usp=sharin g

Pratiwi, N. K. S. (2018). Pentingnya Peran Orang Tua dalam Pendidikan Karakter Anak Usia Sekolah Dasar. ADI WIDYA: Jurnal Pendidikan Dasar, 3(1 April), 83-91. Retrieved from ejournal.indn.ac.id/index.php/AW/article/view/908 
Deswijaya. A.R (2021). Pendidikan Karakter Orang Tua Terhadap Anak dalam Teks Jawa Dongengipun Suwidak Loro. Edudikara: Jurnal Pendidikan dan Pembelajaran, 6(3), 235-243.

Raco, J. R. (2010). Metode Penelitian Kualitatif: Jenis, Karakteristik dan Keunggulannya (2010th ed.; A. L, Ed.). Retrieved from

https://drive.google.com/file/d/1J9wt9AooBaLbcNB1eGT1TmOBCwlbtv7R/view?usp=sha ring

RI, P. (2003). Undang-Undang Republik Indonesia Nomor 20 Tahun 2003 Tentang Sistem Pendidikan Nasional. Retrieved from https://drive.google.com/file/d/1esa0nWOrcxEz61EyM16YG8d0IFQ2TvAL/view?usp=shari ng

Sultan Hadi Prabowo, Agus Fakhruddin, M. R. (2020). Peran Orang Tua dalam Pembentukan Karakter Anak di Masa Pandemi Covid-19 Perspektif Pendidikan Islam. Al Tadzkiyyah: Jurnal Pendidikan Islam, 11(2), 191-207. Retrieved from http://ejournal.radenintan.ac.id/index.php/tadzkiyyah/article/view/7806

Sutarjo Adisusilo, J. (2013). Pembelajaran Nilai Karakter: Konstruktivisme dan VCT sebagai Inovasi Pendekatan Pembelajaran Afektif (Kedua). Retrieved from https://drive.google.com/file/d/198UokVpR_LgwKtMVtYIFjcF_FNIMumuq/view?usp=shar ing 